\title{
OPTIMALISASI PELAKSANAAN PROGRAM KOLEKTIF UNTUK MENINGKATKAN KOMPETENSI GURU SEBAGAI EVALUATOR DALAM MENYUSUN SOAL UAS DI SDN BAKALAN KECAMATAN SUMOBITO TAHUN PELAJARAN 2018/2019
}

\author{
Umi Latifah \\ SDN Bakalan Sumobito \\ umilatifah1406@gmail.com
}

\begin{abstract}
The principal has an important role in leading the school to realize better education. In school-based management, the implementation of school programs is supported by democratic and professional leadership. The principal is a professional education manager. Therefore it is necessary to improve the ability of the board of teachers who become partners in the education unit they lead in terms of assessing the learning process both in the process of making, implementing and analyzing it. Basically, this assessment aims to make the Bakalan Elementary School teacher have the ability to compile the Final Examination Test questions (UAS) properly in accordance with the rules of writing correct questions. This research is based on the formulation of the problem: Whether by optimizing the implementation of the Collective program that has been compiled can improve teacher competency as an Evaluator in compiling the test questions End of Semester (UAS) in SDN Bakalan Sub-district Sumobito Jombang district in the school year of 2018/2019. The method needed in this study was obtained through observing the processing of activities compiling the End of Semester questions through Collective program activities. Based on data analysis, from this study it can be concluded that the application of the Collective program in compiling the End of Semester Test (UAS) is very effective. Through the Collective program can also improve the ability of teachers in compiling a good test this is seen in the first cycle and cycle activities second, with a very significant increase, from an average value of 66.7 with a percentage of completeness of $45.5 \%$ to an average test score of 85.7 with a percentage of completeness of $100 \%$. Tests are considered feasible if at least $75 \%$ of the criteria can be met.Thus in the first cycle $100 \%$ of teachers were able to compile the End of Semester Test (UAS).
\end{abstract}

Keywords: Collective Program in compiling UAS questions

Abstrak : Kepala sekolah memiliki peranan penting dalam memimpin sekolah untuk mewujudkan pendidikan yang lebih baik. Dalam manajemen berbasis sekolah, pelaksanaan program-program sekolah didukung oleh adanya kepemimpinan yang demokratis dan professional. Kepala sekolah adalah manager pendidikan professional. Oleh karena itu perlu meningkatkan kemampuan dewan guru yang menjadi mitra kerja dalam satuan pendidikan yang dipimpinnya dalam hal penilaian proses pembelajaran baik dalam proses pembuatan, pelaksanaan maupan dam menganalisanya. Penilaian ini pada dasarnya bertujuan adalah agar guru SDN Bakalan memiliki kemampuan dalam menyusun soal tes Ulangan Akhir Semester (UAS) dengan baik sesuai dengan kaidah penulisan soal yang benar. Penelitian ini berdasarkan rumusan permasalahan: Apakah dengan mengoptimalkan pelaksanaan program Kolektif yang telah disusun dapat meningkatkan kompetensi guru sebagai Evaluator dalam menyusun soal tes Ulangan Akhir Semester (UAS) di SDN Bakalan kecamatan Sumobito kabupaten Jombang tahun pelajaran2018/2019. Metode yang diperlukan dalam penelitian ini diperoleh melalui observasi pengolahan kegiatan menyusun soal Ulangan Akhir Semester melalui kegiatan program Kolektif. Berdasarkan analisis data, dari penelitian ini dapat ditarik kesimpulan bahwa penerapan program Kolektif dalam menyusun tes Ulangan Akhir Semester (UAS) sangat efektif. Melalui program Kolektif pula dapat meningkatkan kemampuan guru di dalam menyusun tes yang baik hal ini terlihat pada kegiatan siklus pertama dan siklus kedua dengan peningkatan yang sangat signifikan yaitu dari rata rata nilai 66,7 dengan prosentase ketuntasan $45,5 \%$ menjadi ratarata nilai tes 85,7 dengan prosentase ketuntasan $100 \%$. Tes dikatakan layak apabila minimal $75 \%$ kriteria bisa terpenuhi. Dengan demikian pada siklus pertama $100 \%$ guru sudah mampu menyusun tes Ulangan Akhir Semester ( UAS).

Kata kunci : program, kolektif, soal, UAS 
Menjadi seorang kepala sekolah merupakan tanggung jawab yang sangat besar. Kepala sekolah memiliki peranan penting dalam memimpin sekolah untuk mewujudkan pendidikan yang lebih baik. Dalam manajemen berbasis sekolah,pelaksanaan program-program sekolah didukung oleh adanya kepemimpinan yang demokratis dan professional. Kepala sekolah adalah manager pendidikan professional. Oleh karena itu perlu meningkatkan kemampuan dewan guru yang menjadi mitra kerja dalam satuan pendidikan yang dipimpinnya dalam hal penilaian proses pembelajaran baik dalam proses pembuatan, pelaksanaan maupan dalam menganalisanya.Penilaian pada dasarnya bertujuan untuk mendapatkan informasi tentang perkembangan proses dan hasil belajar para peserta didik dan hasil mengajar guru . Informasi mengenai hasil penilaian proses dan hasil belajar serta hasil mengajar yaitu berupa penguasaan indikator - indikator darikompetensi dasar yang telah ditetapkan.

Menyusun tes hasil belajar satu tahun pelajaran bertujuan untuk mengukur keberhasilan siswa dalam menguasai indikator - indikator kompetensi dasar di semester genap dan semester genap dengan melihat hasilnya guru akan mengetahui kelemahan siswa.

Penilaian pada dasarnya bertujuan untuk mendapatkan informasi tentang perkembangan proses dan hasil belajar para peserta didik dan hasil mengajar guru (Ahmadi \& Widodo, 2012) Untuk dapat menyusun tes yang memenuhi persyaratan cukup sulit karena menyusun tes memerlukan pengetahuan, keterampilan serta ketelitian yang cukup tinggi.

Menyusun tes untuk mengetahui tingkat kemampuan akademik pada semester genap supaya dapat menarik kesimpulan apakah siswa bersangkutan telah menguasai indikator - indikator kompetensi dasar atau tidak. Menurut Suharsimi (Arikunto, 2008) tes dibedakan menjadi dua yaitu tes objektif dan tes subjektif. Ada empat macam tes objektif, yaitu tes jawaban benar-salah (true-false), pilihan ganda (multiple choice), isian (completion), dan penjodohan (matching) (Nurgiyantoro, 2001)

(Grounlond and Linn, 1995) menyatakan bahwa tes yang baik harus memenuhi tiga karakteristik, yaitu: validitas, reliabilitas, dan Usabilitas. (Sugiyono, 2015) juga menyatakan bahwa tes yang baik adalah tes yang valid artinya mengukur apa yang hendak diukur. (Nitko, 1996) menyatakan bahwa validitas berhubungan dengan interpretasi atau makna dan penggunaan hasil pengukuran peserta didik. (Messick, 1993) menjelaskan bahwa validitas tes merupakan suatu integrasi pertimbangan evaluatif derajat keterangan empiris yang mendasarkan pemikiran teoritis yang mendukung ketepatan dan kesimpulan berdasarkan pada skor tes.

Seperti yang diungkapkan (Kunandar, 2015), tujuan penyusunan soal hasil belajar peserta didik adalah (1) melacak kemajuan peserta didik, (2) mengecek ketercapaian kompetensi peserta didik, (3) mendeteksi kompetensi yang belum dikuasai oleh peserta didik, dan (4) menjadi umpan balik untuk perbaikan bagi peserta didik. Kenyataan yang terjadi di sekolah bahwa guru kurang mampu menyusun tes. Biasanya menggunakan tes yang sudah ada kemudian disesuaikan dengan materi ajar. Keadaan ini juga terjadi di SDN Bakalan, sehingga sering terjadi tidak tepat antara tes dengan kompetensi dasar yang disyaratkan dalam Kurikulum Tingkat Satuan Pendidikan (KTSP). Di sisi lain guru sebagian besar belum bisa menyusun tes, sehingga sering mencari dari beberapa kumpulan soal yang sudah ada. Setiap penyelenggaraan ulangan akhir semester kadang - kadang tes tersebut secara utuh dapat ditampilkan lagi pada tahun berikutnya.

Peneliti menemukan kenyataan di lapangan setelah observasi dalam penulisan tes hasil belajar satu tahun sebagaian besar guru SDN Bakalan masih mengalami kesulitan dalam penyusunan 
tes yang baik. Dengan demikian maka kemampuan guru perlu ditingkatkan utamanya dalam menyusun tes yang baik untuk Ulangan Akhir Semester (UAS).

Adapun permasalahan yang terdapat dalam menyusun tes yang baik adalah sebagai berikut :

1. Guru belum mampu menyusun kalimat pertanyaan dengan mengacu tujuan pembelajaran yang ada.

2. Guru belum mampu menentukan tingkat kesukaran suatu soal sesuai dengan aspek Taksonomi Bloom

3. Guru belum memahami jenis soal sesuai aspek perilaku Taksonomi Bloom

4. Guru belum mampu mempergunakan bahasa Indonesia yang benar dan baik.

Permasalahan yang peneliti temukan di atas sejalan dengan apa yang disamapaikan oleh (Osnal, O., Suhartoni, S., \& Wahyudi, 2015) guru dalam mengukur kemampuan peserta didik hanya menggunakan tes yang sudah ada kemudian disesuaikan dengan materi ajar. Tidak jarang guru menggunakan soal tes yang sama dengan soal tes pada tahun lalu.hal ini terjadi karena guru belum mampu menyusun butir butir soal dengan tujuan pembelajaran yang ingin dicapai.

Melihat kondisi seperti ini guru belum memiliki kemampuan untuk menyusun tes dan belum pernah mencoba menyusun tes hasil karya sendiri. Sehubungan hal tersebut maka melaksanakan optimalisasi pelaksanaan program kolektif. (Safari, 2008) mengemukakan bahwa tujuan penelaahan adalah untuk mengkaji dan menelaah setiap butir soal agar agar diperoleh butir soal yang bermutu sebelum soal dipergunakan. Untuk meningkatkan kompetensi guru sebagai evaluator dalam menyusun soal PAS di SDN Bakalan Kecamatan Sumobito tahun pelajaran 2018/2019 agar guru SDN Bakalan memiliki kemampuan dalam menyusun soal tes Penilaian Akhir Semester (PAS) dengan baik sesuai dengan kaidah penulisan soal yang benar.

\section{METODE}

Pelaksanaan Penelitian Tindakan Sekolah (PTS) ini dengan subjek penelitian semua guru SDN Bakalan
Kecamatan Sumobito Kabupaten Jombang tahun pelajaran 2018/2019 yang berjumlah 10 guru dengan rincian 1 Kepala sekolah, 6 guru kelas, 1 guru Pendidikan Agama Islam dan 1 guru Penjas dan 1 guru mulok agama .

Adapun lokasi penelitian yang penulis tetapkan adalah SDN Bakalan Kecamatan Sumobito Kabupaten Jombang dengan melibatkan 8 guru kelas dan mata pelajaran, di bawah pembinaan peneliti.

Waktu perbaikan dilakukan pada bulan Pebruari sampai April 2019 dengan pelaksanaan 2 Siklus pelaksanaan program Kolektif. Siklus I dilaksanakan pada minggu ke 2, 3 dan 4 bulan Pebruari setiap hari Sabtu sedangkan siklus II dilaksanakan minggu ke 3 dan 4 belan Maret 2019 juga setiap hari sabtu.

\section{HASIL}

Pada bagian ini dikemukakan hasil penelitian siklus I sesuai dengan proposal semua subyek penelitian terdiri dari guruguru SDN Bakalan yang berjumlah 10 orang. Semua guru tersebut sudah siap dengan perlengkapannya untuk mengikuti program Kolektif penyususan tes hasil belajar semester genap.Untuk menjawab masalah penelitian diadakan dua siklus sesuai dengan proposal, tetapi setelah diadakan penelitian ternyata tidak sampai pada dua siklus. Pada siklus I semua guru di masing-masing kelompok mata pelajaran sudah bisa menyelesaikan sesuai dengan ketentuan yang dipersyaratkan.

\section{Siklus I}

Dalam siklus I terdiri dari perencanaan, pelaksanaan, observasi, dan refleksi yang akan diuraikan sebagai berikut :

\section{a) Perencanaan dengan langkah - langkah sebagai berikut:}

1. Pertemuan semua guru kelasSDN Bakalan berjumlah 9 orang dengan undangan Kepala Sekolah.

2. Menentukan jadual Program Kolektif sebanyak 3 kali pertemuan.

3. Menyuruh guru - guru membawa bahan menyusun soal tes Ulangan Akhir Semester (UAS) seperti silabus, 
RPP dan format Kisi - kisi penulisan soal tes.

4. Memberikan informasi tentang teknik penyusun soal tes.

5. Tanya jawab seputar persiapan program Kolektif

6. Menyampaikan materi Program Kolektif yakni ; pengarahan Kepala Sekolah dan teori menyusun soal tes dari Tenaga ahli yang relevan.

7. Mengelompokkan guru menjadi dalam 5 kelompok sesuai bidang ilmu yaitu kelompok Matematika, kelompok IPS, Kelompok IPA, Kelompok Bahasa dan Kelompok lainnya.

8. Guru diberikan tugas menyusun soal tes Pilihan Ganda untuk setiap soal tes dengan 4 option.

9. Guru diberikan tugas menyusun tes hasil belajar akhir semester bentuk obyektif (Pilihan Ganda) untuk setiap soal dengan 4 option, isian dan jawaban singlat.

10. Jumlah tes yang disusun untuk kelompok Maematika 50 soal, kelompok IPS 50 soal, kelompok IPA 50 soal, kelompok Bahasa 50 soal, kelompok lainnya 50 soal.

11. Peneliti melakukan kros cek ke masing- masing kelompok guru.

12. Presentasi kecil di masing - masing kelompok

13. Presentasi pada pleno.

14. Setelah tes tersusun dilakukan kalibrasi /validasi Teoritik melalui 3 5 orang pakar/guru senior dengan parameter penilaian :

a. Kesesuaian sistem tes dengan tujuan pembelajaran

b. Kesesuaian sistem tes dengan aspek pengetahuan yang diukur $(\mathrm{C} 1-\mathrm{C} 6)$.

c. Penggunaan Bahasa Indonesia yang baik dan benar sesuai dengan EYD.

15. Penentuan tes yang baik

Dari 50 soal tes untuk kelompok Matematika, 50 soal untuk kelompok IPS, 50 soal untuk kelompok IPA, 50 soal untuk kelompok Bahasa, dan 50 soal untuk kelompok lainnya akan dilakukan penilaian dengan 4 bidang kriteria penilaian dan oleh $3-5$ orang pakar guru senior .
16. Parameter akhir kelompok Matematika 50 soal, kelompok IPS 50 soal yang baik, kelompok IPA 50 soal yang baik, kelompok Bahasa 50 soal yang baik dan kelompok lainnya 50 soal yang baik.

b) Pelaksanaan dengan langkah langkah sebagai berikut :

1. Memberikan jadual pelaksanaan Program Kolektif kepada guru - guru SDN Bakalan.

2. Berkoordinasi dengan Kepala Sekolah meminta surat undangan untuk mengumpulkan guru - guru SDN Bakalan .

3. Menyiapkan tempat pelaksanaan Program Kolektif sekaligus mencek keberadaan sarana listrik di ruang/tempat pelaksanaan Program Kolektif .

4. Mempersiapkan snack untuk peserta Program Kolektif selama 3 kali pertemuan dengan kegiatan mulai pk. 8.00 WIB sampai pk. 11.30 WIB.

5. Melaksanakan Program Kolektif sesuai rencana siklus I sebanyak 3 kali pertemuan

6. Pelaksanaan hari I mulai pk. 8.00 WIB sampai pk. 11.30 WIB dengan materi ; pengarahan Kepala Sekolah, Materi penyusunan tes,mengecek kelengkapan bahan - bahan untuk menyusun tes.

7. Pelaksanaan hari II mulai pk. 8.00 WIB sampai pk. 11.30 WIB dengan materi ; menyusun kisi - kisi tes, tanya jawab, presentasi pada kelompok kecil, revisi

8. Pelaksanaan hari III mulai pk. 8.00 WIB sampai pk. 11.30 WIB dengan materi penulisan tes, presentasi pleno, produk akhir.

\section{c) Observasi}

Dilakukan dengan tahapan - tahapan pelaksanaan seperti :

1. Kehadiran guru-guru

2. Kelengkapan bahan - bahan untuk menyusun tes seperti Silabus, RPP, Buku materi/buku pegangan siswa dan guru, format kisi - kisi tes.

3. Kesiapan mental guru - guru untuk mengikuti Program Kolektif selama 3 kali pertemuan

4. Hasil akhir kerja . 
5. Kegiatan observasi disiapkan pedoman dalam bentuk tabel.

\section{d. Refleksi}

Dalam refleksi akan menempuh beberapa kegiatan sebagai berikut :

1. Menentukan indikator pencapaian keberhasilan yaitu a. Kelompok Matematika menghasilkan 50 soal, b. Kelompok IPA menghasilkan 50 soal, c. Kelompok IPS mengasilkan 50 soal, $d$. Kelompok Bahasa mengasilkan 50 soal, e. Kelompok lainnya menghasilkan 50 soal.

2. Guru yang mencapai indikator di atas (point 1) dikategorikan berhasil, sehingga tidak perlu diikutkan dalam silkus II. Sedangkan guru yang belum mencapai indikator di atas wajib ikut dalam siklus II.

\section{Siklus II}

Dalam siklus II terdiri dari perencanaan, pelaksanaan, observasi, dan refleksi yang akan diuraikan sebagai berikut :

a) Perencanaan dengan langkah langkah sebagai berikut :

1. Pertemuan semua guru kelas SDN Bakalan berjumlah 9 orang dengan undangan Kepala Sekolah.

2. Menentukan jadwal Program Kolektif sebanyak 2 kali pertemuan.

3. Menyuruh guru - guru membawa bahan menyusun soal tes Ulangan Akhir Semester (UAS) seperti silabus, RPP dan format Kisi - kisi penulisan soal tes.

4. Memberikan informasi tentang teknik penyusun soal tes.

5. Tanya jawab seputar kesulitankesulitan yang dihadapai guru pada siklus I

6. Menyampaikan materi Program Kolektif dari Tenaga ahli yang relevan.

7. Mengelompokkan guru menjadi dalam 5 kelompok sesuai bidang ilmu yaitu kelompok Matematika, kelompok IPS, Kelompok IPA, Kelompok Bahasa dan Kelompok lainnya.

8. Guru diberikan tugas menyusun soal tes Pilihan Ganda untuk setiap soal tes dengan 4 option, isian dan uraian.
9. Guru diberikan tugas menyusun tes hasil belajar akhir semester bentuk obyektif (Pilihan Ganda) untuk setiap soal dengan 4 option, isian dan uraian.

10. Jumlah tes yang disusun untuk kelompok Maematika 50 soal objektif, kelompok IPS 50 soal, kelompok IPA 50 soal, kelompok Bahasa 50 soal, kelompok lainnya 50 soal.

11. Peneliti melakukan kros cek ke masingmasing kelompok guru .

12. Presentasi kecil di masing - masing kelompok

13. Presentasi pada pleno.

14. Setelah tes tersusun dilakukan kalibrasi /validasi Teoritik melalui $3-5$ orang pakar/guru senior dengan parameter penilaian :

a) Kesesuaian sistem tes dengan tujuan pembelajaran

b) Kesesuaian sistem tes dengan aspek pengetahuan yang diukur $(\mathrm{C} 1-\mathrm{C} 6)$.

c) Penggunaan Bahasa Indonesia yang baik dan benar sesuai dengan EYD.

15. Penentuan tes yang baik

Dari 50 soal tes untuk kelompok Matematika, 50 soal untuk kelompok IPS,50 soal untuk kelompok IPA, 50 soal untuk kelompok Bahasa, dan 50 soal untuk kelompok lainnya akan dilakukan penilaian dengan 4 bidang kriteria penilaian dan oleh $3-5$ orang pakar guru senior .

16. Parameter akhir kelompok Matematika 50 soal, kelompok IPS 50 soal yang baik, kelompok IPA 50 soal yang baik, kelompok Bahasa 50 soal yang baik dan kelompok lainnya 50 soal yang baik.

b) Pelaksanaan dengan langkah langkah sebagai berikut :

1. Memberikan jadwal pelaksanaan Program Kolektif kepada guru guruSDN Bakalan.

2. Berkoordinasi dengan Kepala Sekolah meminta surat undangan untuk mengumpulkan guru - guru SDN Bakalan .

3. Menyiapkan tempat pelaksanaan Program Kolektif sekaligus mencek keberadaan sarana listrik di 
ruang/tempat pelaksanaan Program Kolektif .

4. Mempersiapkan snack untuk peserta Program Kolektif selama 2 kali pertemuan dengan kegiatan mulai pukul 8.00 WIB sampai pukul 11.30 WIB.

5. Melaksanakan Program Kolektif sesuai rencana siklus II sebanyak 2 kali pertemuan

6. Pelaksanaan hari I mulai pk. 8.00 WIB sampai pk. 11.30 WIB dengan materi ; pengarahan Kepala Sekolah, Materi penyusunan tes, mengecek kelengkapan bahan-bahan untuk menyusun tes.

7. Pelaksanaan hari II mulai pk. 8.00 WIB sampai pukul 11.30 WIB dengan materi; menyusun kisi - kisi tes, tanya jawab, presentasi pada kelompok kecil, revisi dan materi penulisan tes, presentasi pleno, produk akhir.

c) Observasi

Dilakukan dengan tahapan- tahapan pelaksanaan seperti :

1. Kehadiran guru-guru

2. Kelengkapan bahan-bahan untuk menyusun tes seperti Silabus, RPP, Buku materi/buku pegangan siswa dan guru, format kisi-kisi tes.

3. Kesiapan mental guru-guru untuk mengikuti Program Kolektif selama 3 kali pertemuan

4. Hasil akhir kerja .

5. Kegiatan observasi disiapkan pedoman dalam bentuk tabel.

\section{d) Refleksi}

Dalam refleksi akan menempuh

beberapa kegiatan sebagai berikut :

1. Menentukan indikator pencapaian keberhasilan yaitu a. Kelompok Matematika menghasilkan 50 soal, b. Kelompok IPA menghasilkan 50 soal, c. Kelompok IPS mengasilkan 50 soal, d. Kelompok Bahasa mengasilkan 50 soal, e. Kelompok lainnya menghasilkan 50 soal.

2. Guru yang mencapai indikator di atas (point 1) dikategorikan berhasil, sehingga tidak perlu diikutkan dalam silkus III. Sedangkan guru yang belum mencapai indikator di atas wajib ikut dalam siklus III

\section{PEMBAHASAN}

\section{Deskripsi kegiatan penelitian}

Penelitian tentang upaya meningkatkan kemampuan guru dalam menyusun tes Ulangan Akhir Semester (UAS) melalui program Kolektif di SDN Bakalan dilaksankan dalam tiga siklus dengan menerapkan program Kolektif dengan ciri sebagai berikut :

a. Mengumpulkan guru dalam satu ruangan

b. Peneliti mendatangkan nara sumber untuk memberikan informasi tetang kostruksi tes.

c. Memberikan binaan secara klasikal

d. Guru mengadakan diskudi dengan teman dalam satu kelompok pengetahuan (Kelompok Matematika, Kelompok IPA, Kelompok IPS, Kelompok Bahasa, dan kelompok lainnya)

e. Penelitian dapat berlangsung dengan baik karena situasi berlangsung terbuka dan kolaboratif.

Dengan menerapkan program Kolektif dalam menyusun tes hasil belajar aktivitas dapat berlangsung dengan baik dan menyenangkan. Kerja sama dalam bentuk diskusi dapat menumbuhkan minat, sikap dan kemauan guru guru untuk melaksanakan tugasnya seperti halnya menyusun tes Ulangan Akhir Semester (UAS) .

\section{Siklus Pertama}

Pada awalnya guru guru merasa tidak siap untuk menyusun tes hasil belajar dengan alasan terbatasnya waktu dan sulitnya menyusun tes sesuai kriteria, karena selama ini guru menyusun tes hasil belajar semester akhir baik ganjil maupun genap dikerjakan dengan mengkompilasi soal soal dari buku buku atau dari kumpulan tes yang sudah ada tanpa mempertimbangkan SK/KD dan indikator dari RPP yang sudah mereka siapkan.

Tetapi setelah penyampaian materi oleh nara sumber yang berupa konstruksi tes, menambah wawasan bagi guru guru 
dalam hal menyusun tes hasil belajar dan guru merasa perlu menyusun tes sesuai kriteria.

\section{a. Hasil obeservasi penyusunan tes siklus I}

Berdasarkan kegiatan yang dilakukan, menunjukkan bahwa ada beberapa aspek yang diamati pada saat proses penyusunan tes Ulangan Akhir Semester berdasarkan pedoman observasi seabagi berikut :

1. Silabus

Silabus yang dimaksudkan dalam penyusunan tes ini adalah silabus kelas I-VI SDN Bakalan semester genap tahun 2018/2019.

2. RPP

RPP (Rencana Pelaksanaan

Pembelajaran) yang dipakai dalam penyusunan tes ini adalah RPP yang dilaksanakan oleh guru guru pada tatap muka di kelas SDN Bakalan semester genap tahun pelajaran 2018/2019.

3. Buku pegangan

Buku pegangan yang dimaksud dalam penyusunan tes ini adalah buku pegangan siswa dan buku referensi yang dipergunakan guru dalam pembelajaran di kelas sesuai dengan yang tercantum dalam RPP untuk tahun pelajaran 2018/2019.

4. Format kisi - kisi tes

Format kisi-kisi tes yang dimaksud dalam penyusunan tes ini adalah format yang memuat tentang SK/KD, indikator, soal, ranah kognitif (C1-C6), dan kunci tes. Format Kisi-Kisi tes disiapkan oleh peneliti .

5. Kesiapan mental

Kesiapan mental yang dimaksudkan dalam penyusunan tes ini adalah kesiapan guru guru untuk mengikuti kegiatan sesuai jadual yang disodorkan peneliti kepada guru guru selama tiga hari melaksanakan program Kolektif .

\section{b. Hasil analisis data penyusunan tes} siklus I

Berdasarkan data di atas maka hasil yang diperoleh pada program Kolektif antara lain :
1. Aspek Silabus dengan rata-rata skor 2,5 menunjukkan bahwa guru telah menyiapkan silabus sebagai bahan penting dalam penulisan kisi-kisi tes.

2. Aspek RPP dengan rata-rata skor 2,7 menunjukkan bahwa guru dalam memilih indikator dan tes yang tercantum dalam RPP sudah relevan.

3. Aspek Buku pegangan dengan ratarata 2,4 menunjukkan bahwa guru sudah memperhatikan referensi yang diperlukan dalam menyusun RPP dan tes.

4. Format kisi-kisi tes dengan rata-rata 2,4 menunjukkan bahwa guru guru dapat menggunakan dengan baik format kisi-kisi yang disiapkan peneliti.

5. Aspek Kesiapan mental dengan ratarata 2,8 menunjukan bahwa guru sudah bersiap dalam mengikuti program Kolektif dalam penyusunan tes hasil belajara akhir semester genap .

Guru yang dianggap memiliki kemampuan di dalam menyusun tes apabila hasilnya memenuhi kriteria tes yang layak seperti kesesuaian bunyi butir dengan tujuan pembelajaran, kesesuaian bunyi soal dengan aspek perilaku yang diukur (C1-C6), penggunaan Bahasa Indonesia yang baik dan benar dan sesuai dengan EYD. Tes dikatakan layak apabila minimal $75 \%$ kriteria bisa terpenuhi.

Data di lapangan menunjukkan dari 11 guru yang diteliti dalam penyusunan tes ini $45,5 \%$ guru sudah tuntas dalam menyusun tes yang baik dengan demikian perlu dilaksanakan siklus II untuk perbaikan penelitian ini.

\section{Siklus kedua}

Pada sikus kedua, nara sumber menyampaikan kembali materi tentang menyusun tes dan lebih banyak memberi kesempatan pada guru untuk bertanya tentang hal-hal yang belum dipahami dalam menyusun soal sesuai kriteria. Adapun hasil pelaksanaan siklus II dapat dilihat pada deskripsi data dibawah ini.

\section{a. Hasil observasi penyusunan tes ulangan akhir siklus II}

Data hasil observasi menunjukkan bahwa ada beberapa aspek yang diamati pada saat proses penyusunan tes Ulangan 
Akhir Semester (UAS) berdasarkan pedoman obsevasi seabagi berikut :

1. Silabus

Silabus yang dimaksudkan dalam penyusunan tes ini adalah silabus kelasl I - VI SDN Bakalan semester genap tahun 2018/2019.

\section{RPP}

RPP (Rencana Pelaksanaan

Pembelajaran) yang dipakai dalam penyusunan tes ini adalah RPP yang dilaksanakan oleh guru guru pada tatap muka di kelasSDN Bakalan semester genap tahun pelajaran 2018/2019.

3. Buku pegangan

Buku pegangan yang dimaksud dalam penyusunan tes ini adalah buku pegangan siswa dan buku referensi yang dipergunakan guru dalam pembelajaran di kelas sesuai dengan yang tercantum dalam RPP untuk tahun pelajaran 2018/2019.

4. Format kisi - kisi tes

Format kisi - kisi tes yang dimaksud dalam penyususnan tes ini adalah format yang memuat tentang SK/KD, indikator, soal, ranah kognitif ( $\mathrm{C} 1-\mathrm{C} 6$ ), dan kunci tes. Format Kisi - Kisi tes disiapkan oleh peneliti .

5. Kesiapan mental

Kesiapan mental yang dimaksudkan dalam penyusunan tes ini adalah kesiapan guru guru untuk mengikuti kegiatan sesuai jadual yang disodorkan peneliti kepada guru guru selama dua hari melaksanakan program Kolektif sebagai pelaksanaan siklus II.

\section{b. Hasil Analisis data penyusunan tes ulangan akhir siklus II}

Berdasarkan analisis data di lapangan maka hasil yang diperoleh pada program Kolektif antara lain :

1. Aspek Silabus dengan rata-rata skor 3,7 menunjukkan bahwa guru telah menyiapkan silabus sebagai bahan penting dalam penulisan kisi-kisi tes.

2. Aspek RPP dengan rata-rata skor 3,6 menunjukkan bahwa guru dalam memilih indikator dan tes yang tercantum dalam RPP sudah relevan.

3. Aspek Buku pegangan dengan ratarata 3,4 menunjukkan bahwa guru sudah memperhatikan referensi yang diperlukan dalam menyusun RPP dan tes.

4. Format kisi-kisi tes dengan rata-rata 4,0 menunjukkan bahwa guru guru dapat menggunakan dengan baik format kisi-kisi yang disiapkan peneliti.

5. Aspek Kesiapan mental dengan ratarata 3,8 menunjukan bahwa guru sudah bersiap dalam mengikuti program Kolektif dalam penyusunan tes hasil belajara akhir semester genap .

Guru yang dianggap memiliki kemampuan di dalam menyusun tes apabila hasilnya memenuhi kriteria tes yang layak seperti kesesuaian bunyi butir dengan tujuan pembelajaran, kesesuaian bunyi soal dengan aspek perilaku yang diukur (C1 - $\mathrm{C} 6)$, penggunaan Bahasa Indonesia yang baik dan benar dan sesuai dengan EYD. Tes dikatakan layak apabila minimal $75 \%$ kriteria bisa terpenuhi.

Data hasil observasi dari 11 guru yang diteliti dalam penyusunan tes ini $100 \%$ guru sudah tuntas dalam menyusun tes yang baik dengan demikian tidak perlu dilaksanakan siklus III .

\section{KESIMPULAN}

Berdasarkan analisis data, dari penelitian ini dapat ditarik kesimpulan bahwa penerapan program Kolektif dalam menyusun tes Ulangan Akhir Semester (UAS) sangat efektif. Sikap dan kemampuan guru SDN Bakalan setelah program Kolektif merasa puas karena melalui program Kolektif dapat mempergunakan waktu sehingga tidak tertunda - tunda. Melalui program Kolektif pula dapat meningkatkan kemampuan guru di dalam menyusun tes yang baik hal ini terlihat pada kegiatan siklus pertama dan siklus kedua dengan peningkatan yang sangat signifikan yaitu dari rata rata nilai 66,7 dengan prosentase ketuntasan $45,5 \%$ menjadi rata-rata nilai tes 85,7 dengan prosentase ketuntasan $100 \%$. Tes dikatakan layak apabila minimal $75 \%$ kriteria bisa terpenuhi.

Dengan demikian pada siklus pertama $100 \%$ guru sudah mampu menyusun tes Ulangan Akhir Semester (UAS) . 


\section{SARAN}

Karena adanya pengaruh positif terhadap penerapan program Kolektif untuk menyusun tes hasil belajar baik dapat meningkatkan minat, motivasi maupun kemampuan guru khusunya dalam menyusun tes yang baik maka melalui kesempatan ini penulis mengajukan beberapa saran:

1. Kepada Kepala Sekolah disarankan dalam menyusun tes hasil belajar akhir semester hendaknya menyelenggarakan program Kolektif agar kerja sama guru dan saling tukar informasi dapat terbina dengan baik dalam mewujudkan meningkatkan mutu sekolah.

2. Kepada semua guru dalam melaksanakan tugas untuk menyusun tes sangat perlu mengadakan kerja sama dan bertukar pikiran dengan guru mata pelajaran lain.

\section{DAFTAR RUJUKAN}

Ahmadi, \& Widodo, S. (2012). Psikologi Belajar. Rineka Cipta.

Arikunto, S. (2008). Dasar Dasar Evaluasi Pendidikan. PT. Bumi Aksara.

Grounlond and Linn. (1995). Measurement and Assessment in Teaching (P. Hall (ed.)).

Kunandar. (2015). Penilaian Autentik. Suatu Pendekatan Praktis. PT Raja

\section{Grafindo Persada.}

Messick. (1993). "Validity," Educational Measurement (Third edit). Macmillan.

Nitko, A. J. (1996). Educational Assessment of Students (Second Edi). Merrill an imprint of Prentice Hall Englewood Cliffs.

Nurgiyantoro. (2001). Penilaian dalan Pengajaran Bahasa dan Sastra. (BPFE (ed.)).

Osnal, O., Suhartoni, S., \& Wahyudi, I. (2015). Meningkatkan Kemampuan Guru dalam Menyusun Tes Hasil Belajar Akhir Semester melalui Workshop di KKG Gugus 02 Kecamatan Sumbermalang Tahun 2014/2015. Pancaran Pendidikan, 5(1), 67-82.

Safari. (2008). Analisis Butir Soal: Dengan Manual, Kalkulator Dan Komputer.

Sugiyono. (2015). Metode Penelitian dan Pengembangan (Research and Development). Alfabeta. 